Jurnal Media Agribisnis Vol. 2 No. 1 Tahun 2017 Hal 20 - 27

Media Komunikasi Hasil Penelitian Bidang Ilmu Agribisnis

ISSN 2541-6898

\title{
KAITAN PERSEPSI MASYARAKAT TANI DENGAN PERILAKU PENJUALAN KELAPA SAWIT KE KUD DARMA BAKTI DI DESA TEBO JAYA KECAMATAN LIMBUR LUBUK MANGKUANG KABUPATEN MUARO BUNGO
}

\author{
Hj.Wiwin Alawiyah ${ }^{1^{*}}$, Nida Kemala ${ }^{2^{*}}$ dan Mas'ud ${ }^{3^{*}}$ \\ ${ }^{1}$ Program Studi Agribisnis, Fakultas Pertanian Universitas Batanghari \\ ${ }^{2}$ Program Studi Agribisnis, Fakultas Pertanian Universitas Batanghari \\ Jl. Slamet Riyadi-Broni, Jambi. 36122. Telp. +6274160103 \\ ${ }^{3}$ Alumni Program Studi Agribisnis, Fakultas Pertanian Universitas Batanghari \\ *email korespondesi : wwnalawiyah78@gmail.com
}

\begin{abstract}
The purpose of this research is to see the relation of farmer's perception with the marketing behavior of palm oil to "KUD Dharma Bakti.The research was conducted in Tebo Jaya Village, due to the reason that this location shows that most of society take a livelihood as oil palm farmers. The number of samples are 57 farmers. The research data were descriptif analyzed to find out the people's perception and sales behavior in the community in Tebo Jaya Village. Statistical analysis used is Chi Square test to test the relation of farmer's perception with palm oil mareting behavior. The results showed: 1) perception of farmers toward to the benefits and performance of the cooperation showed that there are $61.40 \%$ has a good, category, while $38.60 \%$ are not good category. 2) The behavior of palm oil marketing to the kooperation showed $68.42 \%$ as high category while $31.58 \%$ have low behavior category. 3) There is no significant correlation between perception of farmer perception and the behavior of palm oil marketing in Tebo Jaya Village.
\end{abstract}

Keyword: Perception, Behavior, Kooperation.

\begin{abstract}
Abstrak
Tujuan dari penelitian ini untuk melihat adanya kaitan persepsi masyarakat tani dengan perilaku penjualan kelapa sawit ke KUD Dharma Bakti di Desa Tebo Jaya Kecamatan Limbur Lubuk Mengkuang Kabupaten Muaro Bungo . Penelitian dilaksanakan di Desa Tebo Jaya, dengan alasan pemilihan lokasi karena Desa Tebo Jaya merupakan salah satu desa yang sebagian besar masyarakatnya bermata pencarian sebagai petani kelapa sawit. Jumlah sampel penelitian sebanyak 57 RTP. Data penelitian dianalisis secara deskriptif dan untuk mengetahui hubungan antara persepsi masyarakat tani dan perilaku penjualan digunakan analisis statistik yaitu uji Chi Square. Hasil penelitian menunjukkan : 1) gambaran persepsi petani dilihat dari manfaat dan kinerja KUD, yang menunjukkan baik $(61,40 \%)$ sedangkan $(38,60 \%)$ masyarakat tani menyatakan kurang baik. 2) Gambaran penilaian perilaku penjualan kelapa sawit dilihat dari tinggi rendahnya frekuensi penjualan kelapa sawit ke KUD yang menunjukkan tinggi $(68,42 \%)$ sedangkan 31,58\% memiliki perilaku penjualan rendah terhadap KUD. 3) Tidak adanya hubungan yang signifikan antara persepsi masyarakat tani dengan perilaku penjualan kelapa sawit di Desa Tebo Jaya yang dinyatakan dengan $\chi^{2}$ hitung $(1,22)$ lebih kecil dari $\chi^{2}$ tabel $(3,841)$ dengan taraf signifikan sebesar 5\%.
\end{abstract}

Kata Kunci : Persepsi, Perilaku dan KUD 
Jurnal Media Agribisnis Vol. 2 No. 1 Tahun 2017 Hal 20 - 27

Media Komunikasi Hasil Penelitian Bidang Ilmu Agribisnis

ISSN 2541-6898

\section{PENDAHULUAN}

Kehidupan koperasi di Indonesia, mulai sejak berdirinya republik ini hingga sekarang belum juga dapat terbebas dari permasalahan yang menghambat perkembangannya. Segi kuantitas (jumlah) angka pertumbuhan koperasi dari tahun ke tahun naik secara signifikan. Seperti pada tahun 2012, KUD berjumlah 6.500 unit, kemudian meningkat menjadi 6.700 unit pada tahun 2013, tersebar di 3.500 kecamatan di Indonesia, seperti halnya di Provinsi Jambi KUD berjumlah 3.400. Setidaknya Kabupaten Bungo terdapat 43 unit KUD.

Pertumbuhan koperasi yang pesat dari segi jumlah, tidak lepas dari peran pemerintah yang tetap berusaha mempertahankan keberadaannya dan mendorong pertumbuhannya. Salah satu kebijakan yang diambil pemerintah untuk memacu perkembangan koperasi adalah memberlakukan peraturan baru untuk koperasi yaitu UU No. 25 Tahun 1992,h yang menggantikan UU No. 12 Tahun 1967. Dalam UndangUndang koperasi yang terbaru terdapat beberapa perubahan mendasar dari UndangUndang Koperasi sebelumnya yang dilakukan pemerintah sebagai usaha agar koperasi tidak semakin ditinggal oleh pelaku-pelaku ekonomi lainnya. Pemerintah telah melakukan banyak usaha untuk memacu perkembangan koperasi mulai pemberian subsidi, kemudahan prosedur pendirian koperasi dan pembinaan koperasi dengan lahirnya Inpres Nomor 18 Tahun 1998, maupun dengan adanya alokasi kredit murah untuk koperasi, dan lain sebagainya.

Berbagai macam maksud baik dari pemerintah tersebut di atas dalam kenyataannya tidak banyak menimbulkan perubahan yang berarti bagi perkembangan koperasi. Demikian pula berbagai macam bantuan teknis, subsidi, dan lain-lain tidak didukung dengan kesiapan sistem organisasi dan bisnis di tingkat institusi koperasi, maka bantuan tersebut dinilai kurang berarti untuk meningkatkan perkembangan dan kemandirian koperasi. Jenis koperasi yang mampu bertahan terutama di daerah pedesaan yaitu Koperasi Kredit atau credit union. Realisasi dari cara bekerja lembaga ini yaitu dengan menghimpun simpanan-simpanan di antara anggota-anggotanya kemudian dari hasil simpanan tersebut diatur penggunaannya di antara anggota secara bergantian dalam bentuk pinjaman yang di kemudian hari dalam tempo tertentu harus dilunasi.

Jenis Koperasi Kredit ini banyak berkembang di kalangan masyarakat desa, disebabkan karena kondisi desa dan masyarakatnya begitu membutuhkan investasi pembangunan, baik dalam bentuk aliran modal atau kredit yang bisa membantu kesulitan-kesulitan ekonomi yang sering dialami. Oleh karena itu kehadiran Koperasi kredit di desa sangat diperlukan terutama untuk masyarakat yang kurang mampu di daerah pedesaan terutama dalam pengembangan sektor pertanian .

Sektor pertanian merupakan salah satu sektor penting di Indonesia yang berperan sebagai sumber utama pangan dan pertumbuhan ekonomi. Peranan sektor ini di Indonesia masih dapat ditingkatkan lagi apabila dikelola dengan baik karena belum optimalnya penggarapan sampai saat ini.

Kelapa sawit merupakan salah satu tanaman perkebunan yang mempunyai peran penting bagi subsektor perkebunan. Perkembangan kelapa sawit antara lain memberikan manfaat dalam peningkatan pendapatan petani dan masyarakat, produksi yang menjadi bahan baku industri pengolahan yang menciptakan nilai tambah di dalam negeri (produksi tahun 2007 sebesar16,89 juta ton), ekspor yang menghasilkan devisa (sebesar 
Jurnal Media Agribisnis Vol. 2 No. 1 Tahun 2017 Hal 20 - 27

Media Komunikasi Hasil Penelitian Bidang Ilmu Agribisnis

ISSN 2541-6898

7,86 miliar USD) dan menyedikan kesempatan kerja $\pm 4,5$ juta jiwa. (Indonesia Palm Oil Statistic, 2007).

Dari luas areal kelapa sawit rakyat ini, disamping perkebunan plasma, sebagian besar adalah perkebunan swadaya yang berinvestasi menggunakan dana sendiri atau pinjaman, termotivasi oleh pengalaman sukses petani lain serta prospek bisnis yang cerah.

Pengembangan perkebunan rakyat secara tepat merupakan salah satu tujuan pemerintah, karena disamping untuk menghasilkan devisa negara juga untuk memperluas kesempatan kerja dan sekaligus juga untuk meningkatkan kesejahteraan rakyat. Kelapa sawit di Indonesia merupakan komoditas unggulan. Luas lahan terus berkembang dan tidak hanya merupakan monopoli perkebunan besar negara atau perkebunan besar swasta. Saat ini perkebunan rakyat sudah berkembang dengan pesat (Sugito, 1992).

Untuk menanggulangi permasalahan tersebut, maka Koperasi Unit Desa (KUD) harus berperan aktif dalam kegiatan perkebunan rakyat kelapa sawit. Dengan ikut handilnya KUD, petani sawit akan merasa lebih terlindungi karena salah satu fungsi KUD adalah mengayomi anggotanya. KUD merupakan organisasi ekonomi yang berwatak sosial yang diselenggarakan oleh masyarakat dan untuk masyarakat itu sendiri yang berguna untuk meningkatkan penghasilan dan kesejahteraan anggota khususnya dan masyarakat pada umumnya.

Keanggotaan KUD adalah masyarakat perdesaan yang bertempat tinggal di desa yang bersangkutan pada umumnya adalah kepala keluarga dan KUD bermaksud dapat menumbuhkan swadaya serta meningkatkan potensi perdesaan yang berdaya guna dan berhasil guna (Sugito, 1992).

Sedangkan di Kecamatan Limbur Lubuk Mengkuang memiliki 3 unit KUD yang memiliki jumlah anggota lebih dari 100 anggota. Untuk melihat jumlah KUD dan anggota KUD di Kecamatan Limbur Lubuk Mengkuang Kabupaten Muaro bungo dapat dilihat pada tabel dibawah ini :

Tabel 1. Jumlah KUD, dan Jumlah Anggota KUD di Kecamatan Limbur Lubuk Mengkuang Kabupaten Muaro Bungo Tahun 2015

\begin{tabular}{llc}
\hline No & Nama KUD & $\begin{array}{c}\text { Jumlah Anggota } \\
\text { (petani) }\end{array}$ \\
\hline 1 & Dharma Bakti & 382 \\
2 & Tunas Baru & 316 \\
3 & Perintis Utama & 210 \\
\hline & Jumlah & 908 \\
\hline
\end{tabular}

Sumber : BPS Kabupaten Muaro Bungo, 2016

KUD di Desa Tebo Jaya adalah KUD Dharma Bakti yang telah berdiri sejak tahun 1996. KUD tersebut menyediakan segala macam keperluan petani dan juga terkadang memberikan masukan agar petani dapat bekerja optimal. Namun, dalam prakteknya terkadang terjadi perbedaan pendapat antara petani dan KUD sehingga hubungan yang seharusnya terjalin baik justru malah memburuk.

Peran KUD dalam pengembangan potensi hasil pertanian sangat diperlukan, karena KUD memiliki jaringan lebih luas dan petani mendapatkan keuntungan yang adil ketika menjual buahnya kepada KUD daripada tengkulak. Ditambahkan, KUD juga 
Jurnal Media Agribisnis Vol. 2 No. 1 Tahun 2017 Hal 20 - 27

Media Komunikasi Hasil Penelitian Bidang Ilmu Agribisnis

ISSN 2541-6898

menjual alat serta bahan pertanian dengan harga yang lebih terjangkau oleh petani. Dari penjelasan diatas, maka sewajarnya KUD ikut berperan dalam kegiatan perkebunan rakyat kelapa sawit di Desa Tebo Jaya.

Selain itu persepsi masyarakat juga berpengaruh dalam pengembangan KUD dalam suatu lingkungan. Dengan persepsi masyarakat yang berbeda-beda akan menghasilkan tingkat kepercayaan yang berbeda pula. Menurut Irwanto dkk (1996), persepsi merupakan proses aktif yang lebih dari sekedar penginderaan, tetapi sudah merupakan penafsiran pengalaman yaitu dengan melalui proses diterimanya rangsang sampai rangsang tersebut disadari atau dimengerti. Persepsi merupakan proses aktif yang dihasilkan dari apa yang ada di dunia luar dan dari pengalaman, keinginan, kebutuhan, cinta dan kebencian (DeVito, 1995).

Dalam hal ini, petani sawit memiliki persepsi atau pandangan untuk mengukur kapabilitas KUD Dharma Bakti oleh karena itu penulis tertarik untuk melakukan penelitian dengan judul "Kaitan Persepsi Masyarakat Tani Dengan Perilaku Penjualan Kelapa Sawit Ke KUD Dharma Bakti di Desa Tebo Jaya Kecamatan Limbur Mengkuang Kabupaten Muara Bungo".

Berdasarkan uraian di atas, dapat dirumuskan beberapa permasalahan yang akan dibahas pada penelitian ini :

1. Bagaimana gambaran KUD Dharma Bakti ?

2. Bagaimana gambaran persepsi masyarakat terhadap KUD ?

3. Bagaimana gambaran perilaku masyarakat petani dalam penjualan kelapa sawit ?

4. Adakah Kaitan persepsi petani dengan perilaku penjualan kelapa sawit di daerah penelitian?

Adapun tujuan penelitian adalah untuk mengetahui gambaran KUD Dharma Bakti, gambaran persepsi masyarakat terhadap KUD, gambaran perilaku masyarakat petani dalam penjualan kelapa sawit, dan kaitan persepsi petani dengan perilaku penjualan kelapa sawit di daerah penelitian.

\section{METODOLOGI PENELITIAN}

Penelitian ini dilaksanakan di Desa Tebo Jaya, Kecamatan Limbur Lubuk Mengkuang, Kabupaten Muara Bungo. Diperolehnya desa sebagai lokasi penelitian karena diambil secara sengaja (purposive) dengan pertimbangan bahwa didesa tersebut terdapat KUD Dharma Bakti telah berdiri sejak tahun 1996 yang pastinya telah banyak mengikuti perkembangan tentang perkebunan kelapa sawit di Desa Tebo Jaya. Lingkup kajian penelitian hanya untuk mengetahui gambaran KUD Dharma Bakti, persepsi masyarakat, perilaku penjualan kelapa sawit dan kaitan persepsi dengan perilaku masyarakat tani terhadap KUD Dharma Bakti.

Data yang dikumpulkan dalam penelitian ini bersumber dari data primer dan data sekunder. Data primer diperoleh dari petani sampel melalui wawancara langsung yang dipandu dengan daftar pertanyaan (kuisioner) yang telah disediakan terlebih dahulu sesuai dengan tujuan penelitian, sedangkan data sekunder diperoleh dari laporan primer yang telah diolah lebih lanjut dan disajikan baik oleh pihak pengumpul dan literaturliteratur yang berhubungan dengan penelitian ini. Metode yang digunakan dalam pengumpulan data menggunakan metode survey.

Menurut Winarno (1994), bila populasi cukup homogen, terhadap populasi di bawah 100 dapat digunakan sampel sebesar 50\%, bila populasi di atas 100 dapat 
Jurnal Media Agribisnis Vol. 2 No. 1 Tahun 2017 Hal 20 - 27

Media Komunikasi Hasil Penelitian Bidang Ilmu Agribisnis

ISSN 2541-6898

diambil sampel sebesar $15 \%$, dan juga sampel manusia hendaknya di atas 30 orang besarnya.

Berdasarkan pertimbangan tersebut, maka jumlah sampel yang diambil adalah sebanyak 57 orang yang menjadi anggota KUD Dharma Bakti atau 15\% dari jumlah populasi yaitu 382 orang, dengan teknik pengambilan sampel secara acak (Random sampling) .

Analisis data pada dasarnya merupakan proses yang bertujuan untuk menyederhanakan data yang diperoleh ke dalam bentuk yang mudah dibaca, di mengerti dan di interprestasikan. Metode analisis data yang digunakan adalah metode deskritif. Maka analisis hasil dilakukan dengan cara deskritif kualitatif, yaitu hasil data yang diperoleh dari hasil laporan, wawancara dan hasil pengamatan disusun dan diklarifikasikan yang kemudian dilakukan analisis secara deskriptif.

\section{Identitas Petani}

\section{HASIL DAN PEMBAHASAN}

Identitas petani yang dibahas pada penelitian ini adalahtingkat Pendidikan petani, umur petani, jumlah tanggungan keluarga petani, dan luas lahan petani. Salah satu indikator yang dapat digunakan untuk mengetahui kualitas sumberdaya manusia adalah tingkat pendidikan, sesuai dengan pendapat Sumardi (1997), kemajuan suatu wilayah ditentukan oleh beberapa faktor penting yang mencakup kualitas sumberdaya manusia.

Tabel 2. Distribusi Frekuensi Petani Berdasarkan Jenjang Pendidikan di Desa Tebo Jaya Tahun 2017

\begin{tabular}{llcc}
\hline No & \multicolumn{1}{c}{$\begin{array}{c}\text { Jenjang } \\
\text { Pendidikan }\end{array}$} & $\begin{array}{c}\text { Frekuensi } \\
\text { (orang) }\end{array}$ & $\begin{array}{c}\text { Persentase } \\
(\%)\end{array}$ \\
\hline 1 & SD & 23 & 40,36 \\
2 & SMP & 19 & 33,33 \\
3 & SMA & 15 & 26,31 \\
\hline & Jumlah & 57 & 100
\end{tabular}

Sumber : Data Olahan Primer 2017

Tabel 3. Distribusi Frekuensi Petani Berdasarkan Umur di Desa Tebo Jaya Tahun 2017

\begin{tabular}{cccc}
\hline No & $\begin{array}{c}\text { Kelompok Umur } \\
\text { (Tahun) }\end{array}$ & $\begin{array}{c}\text { Frekuensi } \\
\text { (orang) }\end{array}$ & $\begin{array}{c}\text { Persentase } \\
(\%)\end{array}$ \\
\hline 1 & $30-33$ & 8 & 14,03 \\
2 & $34-37$ & 6 & 10,53 \\
3 & $38-41$ & 13 & 22,81 \\
4 & $42-45$ & 10 & 17,54 \\
5 & $46-49$ & 6 & 10,53 \\
6 & $50-53$ & 7 & 12,28 \\
7 & $54-57$ & 7 & 12,28 \\
\hline
\end{tabular}

Sumber : Data Olahan Primer 2017 
Jurnal Media Agribisnis Vol. 2 No. 1 Tahun 2017 Hal 20 - 27

Media Komunikasi Hasil Penelitian Bidang Ilmu Agribisnis

ISSN 2541-6898

\begin{tabular}{|c|c|c|c|}
\hline No & $\begin{array}{l}\text { Jumlah Tanggungan } \\
\text { keluarga }\end{array}$ & $\begin{array}{c}\begin{array}{c}\text { Frekuensi } \\
\text { (orang) }\end{array} \\
\end{array}$ & $\begin{array}{c}\text { Persentase } \\
(\%)\end{array}$ \\
\hline 1 & 1 & 12 & 21,05 \\
\hline 2 & 2 & 15 & 26,31 \\
\hline 3 & 3 & 16 & 28,07 \\
\hline 4 & 4 & 11 & 19,30 \\
\hline 5 & 5 & 3 & 5,27 \\
\hline 6 & 6 & 0 & 0 \\
\hline 7 & 7 & 0 & 0 \\
\hline & Jumlah & 57 & 100 \\
\hline
\end{tabular}

Sumber : Data Olahan Primer 2017

Tabel 6. Distribusi Frekuensi Petani Berdasarkan Luas Lahan di Desa Tebo Jaya Tahun 2017

\begin{tabular}{cccc}
\hline No & $\begin{array}{c}\text { Luas Lahan } \\
(\mathrm{Ha})\end{array}$ & $\begin{array}{c}\text { Frekuensi } \\
\text { (orang) }\end{array}$ & $\begin{array}{c}\text { Persentase } \\
(\%)\end{array}$ \\
\hline 1 & $1-1,2$ & 13 & 22,81 \\
2 & $1,3-1,5$ & 0 & 0 \\
3 & $1,6-1,8$ & 0 & 0 \\
4 & $1,9-2,1$ & 29 & 50,88 \\
5 & $2,2-2,4$ & 0 & 0 \\
6 & $2,5-2,7$ & 0 & 0 \\
7 & $2,8-3$ & 15 & 26,31 \\
\hline & Jumlah & 57 & 100 \\
\hline
\end{tabular}

Sumber : Data Olahan Primer 2017

\section{Gambaran KUD Dharma Bakti}

Koperasi Unit Desa Dharma Bakti di dirikan pada tahun 1996 yang berada di Desa Tebo Jaya Kecamatan Limbur Lubuk Mengkuang Kabupaten Muaro Bungo yang memiliki luas lahan 0.5 Hektar. Melalui Kepala Unit Pemukiman Transmigrasi (KUPT), maka diadakan rapat pada bulan April 1986 untuk membentuk suatu Koperasi Unit Desa (KUD) di Desa Tebo Jaya. Dalam KUD memiliki ketentuan masing-masing sama halnya pada KUD Dharma Bakti, dalam koperasi Dharma Bakti ini memiliki sistem yang tidak berbeda jauh dengan KUD lainnya seperti halnya dalam pembelian kelapa sawit pada petani. Pembelian yang dilakukan KUD Dharma Bakti bisanya dilakukan dua minggu sekali, berarti dalam satu bulan terdapat dua kali masa panen.

\section{Persepsi Petani terhadap KUD Dharma Bakti}

Persepsi merupakan suatu proses yang mana seseorang mengorganisasikan dan menginterprestasikan kesan-kesan sensorisnya dalam usahanya memberikan suatu makna tertentu pada lingkungannya (Siagian, 1995). Lebih lanjut Siagian mengatakan, persepsi setiap orang dapat berbeda-beda karena persepsi seseorang sangat dipengaruhi oleh keinginan dari individu tersebut.Sementara itu menurut Walgito (2002), persepsi merupakan suatu proses yang didahului oleh proses penginderaan terhadap suatu 
Jurnal Media Agribisnis Vol. 2 No. 1 Tahun 2017 Hal 20 - 27

Media Komunikasi Hasil Penelitian Bidang Ilmu Agribisnis

ISSN 2541-6898

stimulus yang kemudian diorganisasikan dan diinterprestasikan oleh individu, sehingga individu menyadari, mengerti tentang apa yang diindera tersebut.

Tabel 7. Distribusi Frekuensi Masyarakat Tani Berdasarkan Persepsi Terhadap KUD Dharma Bakti di Desa Tebo Jaya 2017

\begin{tabular}{llcc}
\hline No & \multicolumn{1}{c}{ Kategori Persepsi } & $\begin{array}{c}\text { Frekuensi } \\
\text { (Orang) }\end{array}$ & $\begin{array}{c}\text { Persentase } \\
(\%)\end{array}$ \\
\hline 1. & Baik & 36 & 63,16 \\
2. & Kurang Baik & 21 & 36,84 \\
\hline \multicolumn{2}{r}{ Total } & 57 & 100 \\
\hline
\end{tabular}

Sumber : Data Olahan Primer 2017

Berdasarkan hasil analisis didapatkan bahwa ada 21 responden dari jumlah keseluruhan 57 responden yang memiliki persepsi kurang baik dan 36 responden memiliki persepsi baik. Maka didapatkan kesimpulan bahwa persepsi masyarakat terhadap manfaat dan kinerja KUD dapat dikategorikan baik dengan presentase 63,16 $\%$.

\section{Perilaku Masyarakat Petani dalam Penjualan Kelapa Sawit}

Tabel 8. Distribusi Frekuensi Masyarakat Tani Berdasarkan Perilaku Penjualan di Desa Tebo Jaya 2017

\begin{tabular}{cccc}
\hline No. & $\begin{array}{c}\text { Kategori Perilaku } \\
\text { Penjualan }\end{array}$ & Frekuensi & $\begin{array}{c}\text { Persentase } \\
(\%)\end{array}$ \\
\hline 1. & Tinggi & 39 & 68,42 \\
2. & Rendah & 18 & 31,58 \\
\hline \multicolumn{2}{c}{ Total } & 57 & 100 \\
\hline
\end{tabular}

Sumber : Data Olahan Primer 2017

Berdasarkan Tabel di atas diketahui bahwa terdapat 39 responden dari 57 responden yang berperilaku tinggi dalam tingkat penjualan buah sawit kedalam KUD. Maka dapat disimpulkan bahwa masyarakat menerima KUD dengan baik dengan presentase penjualan buah sawit yang tinggi yaitu $68,42 \%$.

\section{Kaitan antara Persepsi Petani dengan Perilaku Penjualan Kelapa Sawit ke KUD di Desa Tebo Jaya Kecamatan Limbur Lubuk Mengkuang Kabupaten Muaro Bungo}

Tabel 9. Tabel $x^{2}$ Kontingensi 2x2 Hubungan antara Variabel Persepsi dengan Perilaku Penjualan Kelapa Sawit 2017.

\begin{tabular}{|c|c|c|c|c|c|c|}
\hline \multicolumn{6}{|l|}{ Persepsi } & $\sum$ \\
\hline & RTP & $\%$ & RTP & $\%$ & RTP & $\%$ \\
\hline Tinggi & 27 & 47,37 & 12 & 21,05 & 39 & 68,42 \\
\hline Rendah & 9 & 15,79 & 9 & 15,79 & 18 & 31,58 \\
\hline$\sum$ & 36 & 63,16 & 21 & 36,84 & 57 & 100 \\
\hline
\end{tabular}

Sumber : Data olahan primer 2017 
Jurnal Media Agribisnis Vol. 2 No. 1 Tahun 2017 Hal 20 - 27

Media Komunikasi Hasil Penelitian Bidang Ilmu Agribisnis

ISSN 2541-6898

Pada perhitungan $x^{2}$ Kontingensi $2 \times 2$ dapat dirincikan bahwa terdapat 27 responden yang memiliki kategori berpersepsi baik pada tingkat perilaku penjualan yang tinggi, 12 responden dengan kategori berpersepsi kurang baik pada tingkat perilaku penjualan yang tinggi, 9 responden dengan kategori berpersepsi baik pada tingkat perilaku penjualan rendah, dan yang terakhir 9 responden berpersepsi kurang baik dengan perilaku tingkat penjualan rendah.

Dari hasil perhitungan dapat diketahui bahwa $x^{2}$ Hitung $(1,22)$ lebih kecil dari $x^{2}$ tabel $(3,84)$ yang menyatakan bahwa tidak ada kaitan antara persepsi masyarakat tani ke KUD dengan perilaku penjualan kelapa sawit. Berarti dalam hal ini, meskipun beberapa petani memiliki persepsi baik, belum tentu berperilaku tinggi dalam penjualan tandan buah sawit tersebut, dan begitu pula sebaliknya.

Persepsi masyarakat $63,16 \%$ baik dan $36,84 \%$ kurang baik. Namun pada perilaku penjualan masyarakat tidak jauh berbeda, hanya $68,42 \%$ tinggi dan $31,58 \%$ rendah. Sehingga terlihat dari hasil penilaian dilapangan tidak adanya keterkaitan satu sama lain antara persepsi masyarakat tani dengan perilaku penjualan tandan kelapa sawit.

\section{KESIMPULAN}

Berdasarkan penelitian dan pembahasan dapat ditarik beberapa kesimpulan sebagai berikut :

1. Gambaran KUD Dharma Bakti di Desa Tebo Jaya bergerak dalam bidang sarana prasarana, bidang jasa, bidang pemasaran, dan bidang lapangan, yang mana KUD memiliki 22 pengurus dan 382 orang anggota merupakan petani sawit yang aktif menjual tandan buah sawit ke KUD.

2. Persepsi masyarakat tani ke KUD Dharma Bakti mayoritas menunjukkan baik $(63,16 \%)$, sedangkan 36,84\% menunjukkan persepsi tidak baik.

3. Perilaku masyarakat tani dalam penjualan tandan kelapa sawit ke KUD berpotensi tinggi dengan pesentase $68,42 \%$, sedangkan yang berperilaku rendah sebanyak $31,58 \%$.

4. Antara persepsi petani ke KUD Dharma Bakti dengan perilaku penjualan kelapa sawit ke KUD di Desa Tebo Jaya tidak memiliki kaitan.

\section{DAFTAR PUSTAKA}

Badan Pusat Statistik Kabupaten Muaro Bungo. 2014. Muaro Bungo Dalam Angka. BPS. Muaro Bungo.

DeVito, Joseph A. 1995. The Interpersonal Communication Book. $7_{\text {th }}$ Edition. New York. Harper Collins College Publisher.

Irwanto, dkk. 1996. Psikologi Umum: Buku Panduan Mahasiswa. PT Gramedia Pustaka Utama. Jakarta.

Siagian, Sondang P. 1995. Teori Motivasi dan Aplikasinya. Rineka Cipta. Jakarta.

Sugito. 1992. Tanaman Perkebunan Di Indonesia. Yogyakarta.

Walgito. 2002. Teori Persepsi dan Aplikasinya. Erlangga. Jakarta.

Winarno.F.G. 2004. Kimia Pangan dan Gizi. PT. Gramedia Pustaka Utama. Jakarta 